\title{
Modelling animal treading impacts on infiltration rate
}

\author{
Y. TIAN, P.L. SINGLETON, G.W. SHEATH, D.G. McCALL and W.T. CARLSON \\ AgResearch, Ruakura Research Centre, Private Bag 3123, Hamilton
}

\begin{abstract}
Sediment and chemical losses in surface runoff can be significant on land with rolling topography. These effects can be more severe in grazed pasture systems because of animal treading damage to the ground surface. The phenomenon of treading includes soil compaction, pugging, creating tracks and surface cracking. Modelling results presented in the paper provide estimation of changes in water infiltration rate with land of different topography, soil physical condition, season and grazing. These models were derived from field data collected over 3 years and were specified for micro-sites $\left(0.5 \mathrm{~m}^{2}\right)$. The modelling results identified that micro-site infiltration analysis was appropriate to land with complex grazing and topographic conditions. The correlation between the model estimation and field measures was up to $73 \%$ (adjusted $\mathrm{R}^{2}$ ).
\end{abstract}

Keywords: animal treading, infiltration rate, soil compaction, runoff, cellular automata, spatial modelling

\section{Introduction}

One of the important issues in the development of sustainable pastoral agriculture in New Zealand is the problem of assessing impacts of animal treading on soil damage and the off-site effects on water quality. Some investigation (Naeth et al. 1991; Ferrero 1994; Proffitt et al. 1995; Sheath \& Boom 1997) on animal treading impacts on farm land have been done previously by interpreting field trial information rather than using a modelling approach. This paper presents a model used to estimate the effects of beef cattle treading impacts on infiltration rate and the subsequent recovery of soil properties.

The model was derived from analysing a series of field experiments on land hydrological properties. The model covers animal treading intensity, soil water content, and soil characteristics under different landscape conditions such as steep and easy slopes, and track and inter-track areas. The discussion focuses on easy and steep land with either clay or ash soil types.
Owing to the highly variable nature of hill land topography, associated soil types, and grazing management, the model was specified for areas of 0.5 $\mathrm{m}^{2}$, and for one rainfall event at any time of the year after a single spring treading event (one grazing in the year). The model will contribute to an up-scaling process which integrates hydraulic properties from these microsites into a larger area or water catchment by using cellular automata mathematical modelling and computer simulation approaches.

\section{Experimental details}

Field data from artificial rainfall simulation (Bowyer et al. 1989) were used in the model development. The experimental objectives were to determine soil infiltration and runoff properties as affected by treading, grazing, land topography and soil type. The trial site was at Whatawhata Research Centre. Trial plots were $0.5 \mathrm{~m}^{2}$.

Rainfall intensities applied by rainfall simulators normally ranged from 55 to $65 \mathrm{~mm} /$ hour. The volume of runoff water was measured for calculation of infiltration rate over time. The initial soil moisture for each plot was measured by taking 10 core samples $(0$ $75 \mathrm{~mm}$ depth) from the surrounding area. Treading damage from a single event was created in July or August. The trial covered three levels of treading damage: control, medium and high. We quantified the damage using quadrate point estimates. The experiment also considered a double treading scenario in which a second treading occurred in September.

After the desired single or double treading damage had occurred, all the plots were caged to prevent further damage through the year. Infiltration using rainfall simulators was measured on each plot in October, December, February and June to determine infiltration recovery rates. Each rainfall simulation lasted at least 80 minutes, by which time infiltration had reached the steady state infiltration rate.

\section{Modelling development}

This study tested the suitability of three popular infiltration equations (Salvucci \& Entekhabi 1994) for use on complex hill grazing land. These infiltration equations are listed below: 
The modified Green \& Ampt equation:

$$
\mathrm{i}=\mathrm{A}+\mathrm{B} / \mathrm{t}
$$

The Philip equation:

$$
\mathrm{i}=\mathrm{A}+\mathrm{B} / \mathrm{t} * 0.5
$$

The Kostiakov equation:

$$
\mathrm{i}=\text { At-B }
$$

where $\mathrm{i}=$ infiltration rate $(\mathrm{mm} /$ hour $)$; $\mathrm{t}=$ elapse time (minute)

$\mathrm{A}, \mathrm{B}=$ parameters.

Our initial analysis showed that the modified Green \& Ampt equation provided a better fit to the observed infiltration data than the other two equations. We then modified the equation to better estimate infiltration changes under animal treading and grazing management.

In the Green \& Ampt equation, parameter $A$ was assumed to represent steady state infiltration rate. The parameter $B$ was related to the fill rate of soil moisture storage before runoff occurs. Parameter $A$ determines the quantity of infiltration over time. This parameter is very important especially during a long period of rainfall. Our first approach was a regression analysis relating soil and hydrology characteristics to parameter $A$.

The parameter $B$ determines the time to start runoff. This parameter determines the slope of the infiltration curve at the beginning of a rainfall event. However, this parameter was not sensitive to infiltration rate unless rainfall was short and light. In this case, there would not be any runoff generated, so $B$ is not so important in this study. $B$ provided a good curvature estimation of the infiltration curve when it was set to a constant between 120 to 150 for each micro-site depending on treading damage, topography and soil characteristics.

Modelling of infiltration rate for a rainfall event was done in two steps:

1. empirical analysis for steady state infiltration rate.

2. calibrating the modified Green \& Ampt equation for the dynamic filling rate of soil moisture storage.

\section{Results}

Empirical functions of infiltration for the scenarios of ash and clay soil on easy slopes were derived by analysing the experimental data. Analysis identified that infiltration recovery rate following treading damage was strongly related to soil characteristics and the degree of treading damage. It also showed that infiltration rate with time responds differently among various land topology.

The modeling process successfully estimated quantitative seasonal changes of steady state infiltration rate throughout the year. It identified that seasonal variation, characteristics of treading damage, bare ground
$\%$, organic matter and land topography were highly correlated to infiltration rate (adjusted $\mathrm{R}^{2}$ value is 0.53 for equation (4) and 0.73 for (5)).

The recovery curves (Figures 1 and 2) of steady state infiltration rate described with regression functions for ash and clay soils types respectively, were generated from the mean steady state infiltration rate from model estimation for each treading treatment: i.e., control, medium damage, high damage and damage from double treading. The empirical formula for clay soil is displayed in equation 4 and for ash soil in equation 5 below:

$\mathrm{f}=-5.28+0.703 * \mathrm{OM}-0.147 * \mathrm{SM}+0.324 *$ Damage $-0.539 *$ Bare

$+11.8 *$ TRT $+0.303 *$ ASC $-0.0208 *$ Days

$\mathrm{f}=31.6-0.416^{*} \mathrm{OM}+0.755^{*} \mathrm{SM}-0.456 * \mathrm{Bare}+5.72 * \mathrm{TRT}+$ $0.0322 *$ Days $+0.418 *$ Slope

where $\mathrm{f}$ is the steady state infiltration rate; $\mathrm{OM}$ is the soil organic matter (\%); SM is the initial soil moisture content; Bare is the bare ground (\%); TRT is the treatment ( 1 or 2 treading events); ASC is the anion storage capacity; Damage is the hoof print area (\%of the plot area); Days is the number of days after treading event; Slope is the degree of the slope of the micro-site.

Figure 1 Model estimation of steady state infiltration for clay.

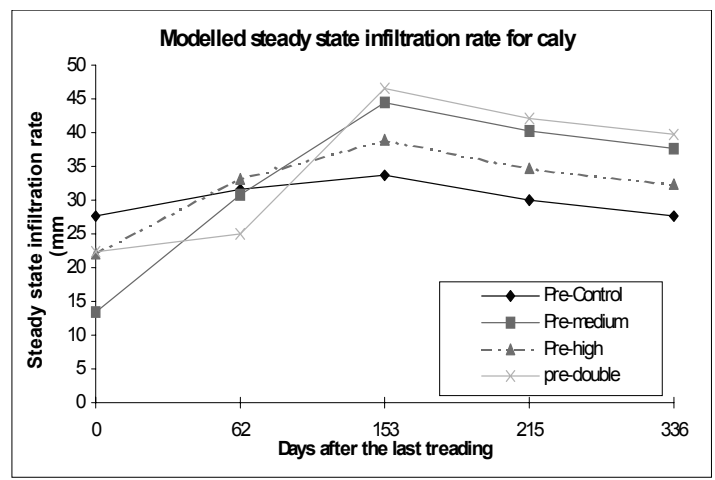

Figure 2 Model estimation of steady state infiltration for ash.

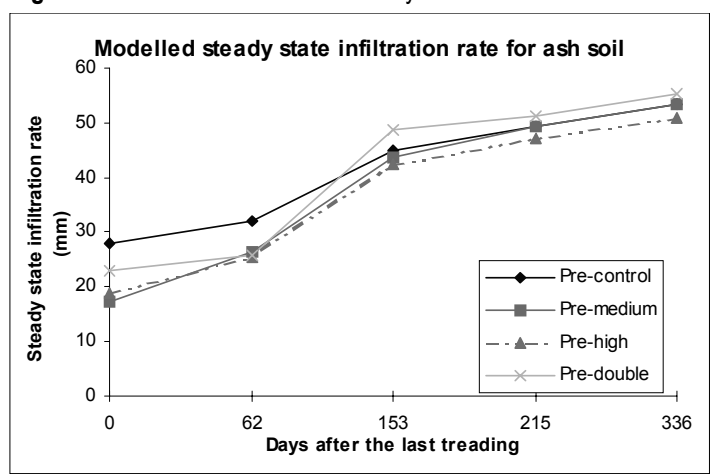


The model estimation of steady state infiltration gave an accurate prediction of infiltration rate for individual rainfall events. However, calibrating parameter $B$ in the Green \& Ampt equation was also important in adjusting the dynamic filling rate of soil moisture storage. Figures 3 and 4 display example model estimations for ash and clay soil on easy slope areas.

Figure 3 Model estimation vs measurement on an ash soil plot for an individual rainfall event.

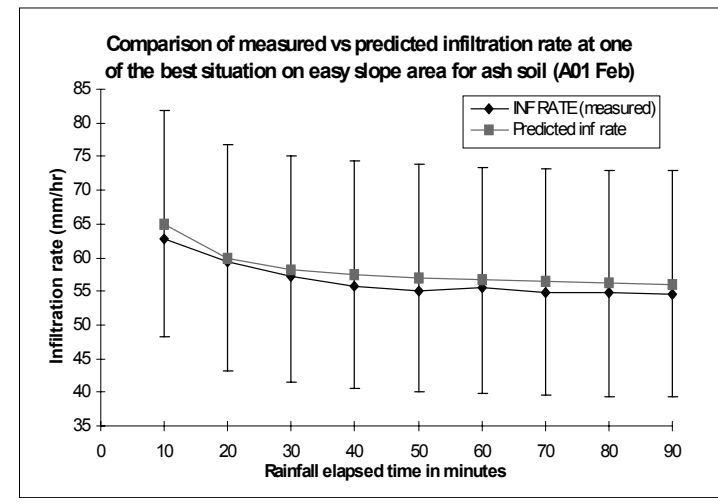

Figure 4 Model estimation vs measurement on a clay soil plot for an individual rainfall event.

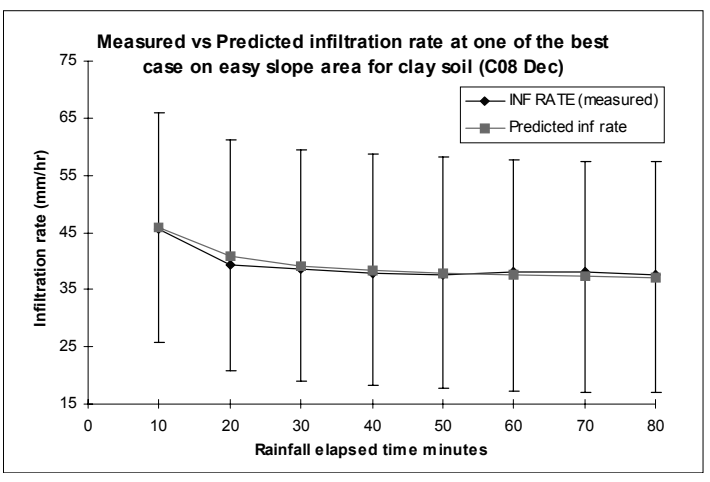

The standard deviation and error range were 8.45 and 16.9 for the ash soil, and 10.1 and 20.2 for the clay soil.

\section{Discussion}

The empirical model developed in the study performed very well in estimating infiltration rate changes in the scale of micro-sites. The accurate infiltration estimation in the micro-site is the appropriate scale for analysis of the detailed mechanics of runoff and associated chemical and sediment losses. Larger scales are useful for revealing large-area dynamics of runoff and erosion, and are the appropriate scale for management strategies. In order to make the model applicable to large areas, a cellular automata (CA) approach was used to transfer information derived from the micro-site scale into field size and yet retain the water flow characteristics between micro-sites. This integration procedure is known as upscaling.

In cellular automata modelling, the dynamic behaviour of the overall system emerges from the interactions of micro-sites (automata) arranged specially in a grid so that any global averaging is minimised or eliminated altogether. Figure 5 shows an example of a field topography (track and inter-track) represented with cellular automata format. This spatial cell interacting system has the advantage of identifying between-site variations in properties and in individual responses (Toffoli \& Morgolus 1987).

Figure 5 The topography of a field with $5 \times 5$ cells. Direction of surface runoff is shown by the arrows.

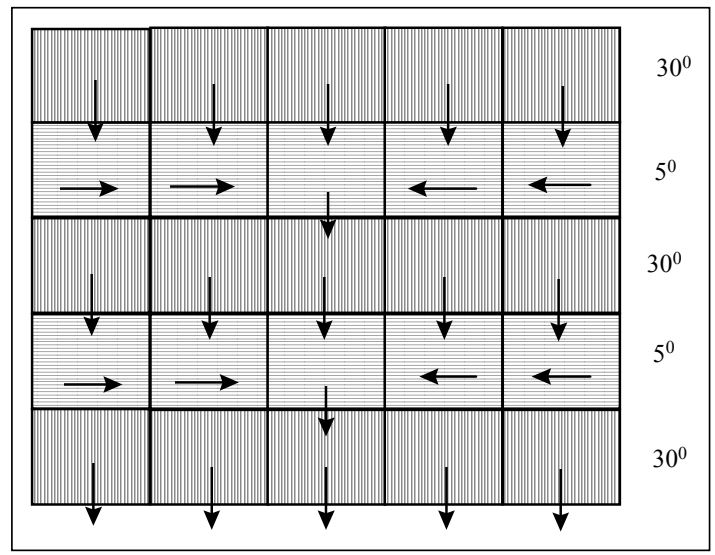

Figure 6 Total runoff for each cell for 60 minutes using the topography in Figure 5.

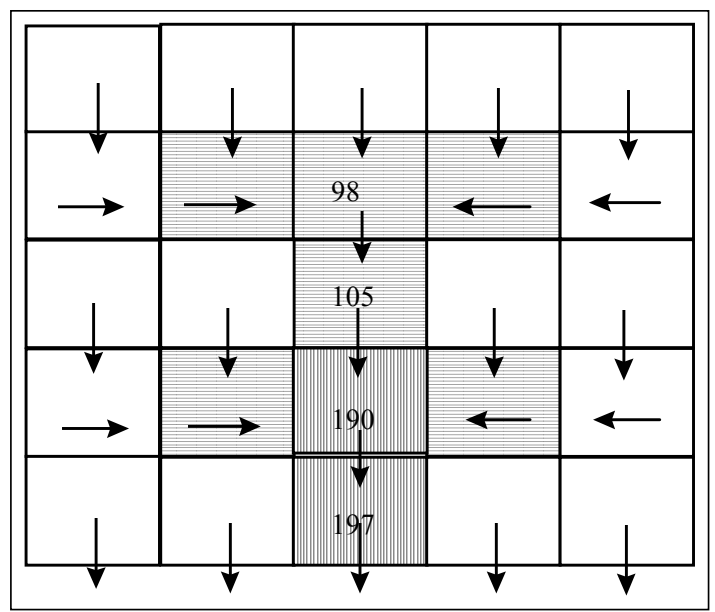


The CA model has been developed with ARC/INFO grid/spatial analyst utilities. Figure 6 shows an example of accumulative effects of runoff for the field in Figure 5. The model could be coupled with other models for prediction of whole catchment effects on runoff water quality resulting from different grazing regimes. The model is of great benefit for improved modelling of nutrient and sediment loss in runoff from hill land with a mixture of tracks, soils, and slopes.

\section{ACKNOWLEDGEMENT}

This project was funded by the New Zealand Foundation of Research Science and Technology (FRST).

\section{REFERENCES}

Bowyer B.; Burt, T.P. 1989. Rainfall simulation for investigating soil response to rainfall. Soil technology 2: 1-16.

Ferrero, A.F. 1994. Soil physical characteristics of hillslope pastures under repeated animal and machinery traffic. International agrophysics 8: 1, 47-51.

Naeth, M.A.; Chanasyk, D.S.; Rothwell, R.L.; Bailey, A.W. 1991. Grazing impacts on soil water in mixed prairie and fescue grassland ecosystems of Alberta. Canadian journal of soil science 71: 3, 313-325.

Proffitt, A.P.B.; Jarvis, R.J.; Bendotti, S. 1995. The impact of sheep trampling and stocking rate on the physical properties of a red duplex soil with two initially different structures. Australian journal of agricultural research 46: 733-747.

Salvucci, G.D.; Entekhabi, D. 1994. Explicit expressions for Green-Ampt (delta function diffusivity) infiltration rate and cumulative storage. Water resources research 30: 2661-2663

Sheath, G.W.; Boom, C.J. 1997. Impact of beef cattle grazing systems on treading damage and forage supply. Proceedings of the New Zealand Grassland Association 59: 87-92.

Toffoli, T.; Morgolus, N. 1987. Cellular Automata Machines: A New Environment for modelling. Cambridge, MA: MIT Press. 